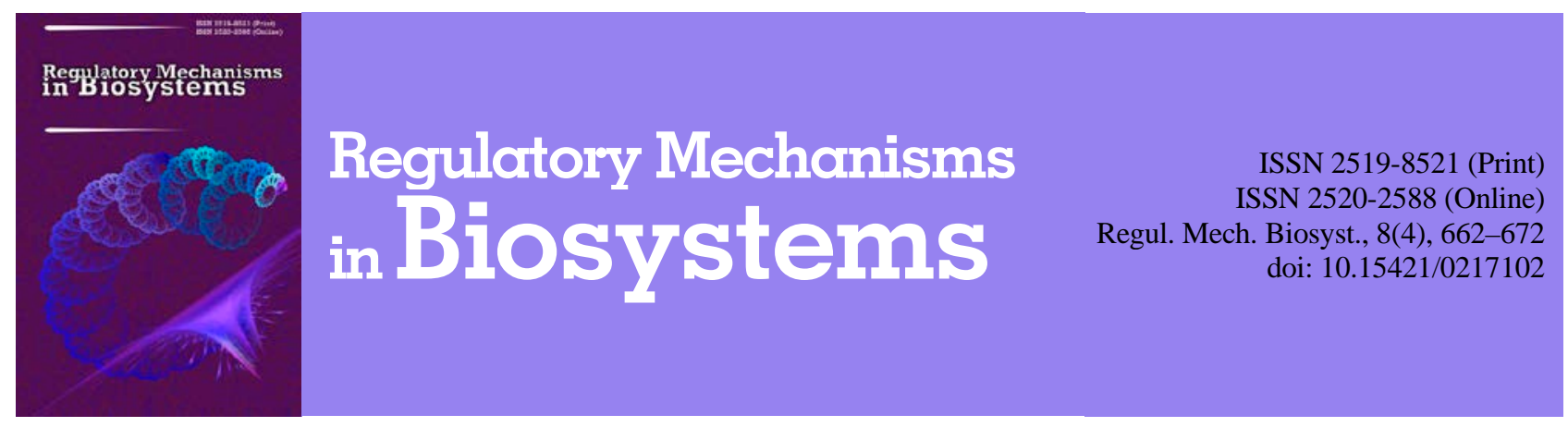

\title{
Pharmaceutical development of complex wound-healing ointment for the needs of military medicine
}

\author{
V. O. Tarasenko*, V. V. Shmatenko*, V. O. Kuchmistov*, N. O. Koziko**, \\ O. P. Shmatenko*, A. O. Drozdova***, V. V. Rudenko*, T. S. Nehoda** \\ *Ukrainian Military Medical Academy, Kyiv, Ukraine \\ **National Medical University named after O. O. Bohomolets, Kyiv, Ukraine \\ ***National Medical Academy of Postgraduate Education named after P. L. Shupyk, Kyiv, Ukraine
}

Article info

Received 27.10.2017

Received in revised form 21.11.2017

Accepted 24.11.2017

Ukrainian Military Medical Academy, Melnikov Str., 24, Kiev, 04050, Ukraine. Tel.: +38-095-838-97-19. E-mail:

vika_tarasenko83@ukr.net

National Medical University named after A. A. Bogomolets, Pushkinskaya Str., 22, Kiev, 01601, Ukraine. Tel.: +38-068-594-67-95. E-mail: fedoritenkonata@ukr.net

National Medical Academy of Postgraduate Education named after P. L. Shupyk, Dorogozhitska Str., 9 Kiev, 04112, Ukraine. Tel.: +38-066-364-84-14. E-mail: drozdova82@ukr.net

Tarasenko, V. O., Shmatenko, V. V., Kuchmistov, V. O., Koziko, N. O., Shmatenko, O. P., Drozdova, A. O., Rudenko, V. V., \& Nehoda, T. S. (2017). Pharmaceutical development of complex wound-healing ointment for the needs of military medicine. Regulatory Mechanisms in Biosystems, 8(4), 662-672. doi:10.15421/0217102

This article presents experimentally proved scientific-practical methods of developing modern vulnerary medical preparations in the form of an ointment with antibacterial, anti-inflammatory and anesthetic properties for the purposes of military medicine. In pursuit of the designated goals, the authors used modern methods of research: pharmacologicaltechnological, physical-chemical, structural-mechanical and biological methods - for proving the compound of the combined ointment including ofloxacin, nimesulide and lidocaine. On the basis of the research conducted, we proved the content and rational technique of the complex antimicrobial ointment with anti-inflammatory and anesthetic effect using ofloxacin $(0.05 \mathrm{~g})$, nimesulide $(1.0 \mathrm{~g})$ and lidocaine $(4.0 \mathrm{~g})$. We experimentally established the optimal content of the main component of the ointment: emulsive base of mixture of Polyethylene Oxide-400 and Polyethylene Oxide-1500 (1:4) and a complex of emulsifiers of the first and the second generations - cetostearylic alcohol $-3 \%$, monoglyceryl stearate $5 \%$ at the constant concentration of paraffin oil $-20 \%$, which involves a certain temperature regime during preparation, a sequence of introducing active pharmacological ingredients and adjuvants to the water and oil phases, frequency and duration of mixing. Physical-chemical tests of the ointment base determined the optimum concentration of glycerine as $5 \%$, which encourages elimination of purulent discharge from damaged tissues, causing an anti-inflammatory effect and providing a prolonged, but milder dehydrating effect. The relation between physical-chemical, rheological, biopharmaceutical properties of the developed preparation and the concentration and method of introduction of the active pharmaceutical ingredients was theoretically and experimentally proven. We conducted pre-clinical studies (in vivo) for defining the therapeutic efficiency of the ofloxacin-nimesulide composition in the compound of the developed ointment for complex treatment of the wound process. We studied the specific activity (anti-alternative - model of standard tissue wounds in rats), which allowed us to establish the optimum concentration of nimesulide, which is $1 \%$. Biopharmaceutical studies (in vitro method) determined the optimum method of introducing ofloxacin, nimesulide and lidocaine in the ointment base as a solution in dimethyl sulfoxide. To select an anesthetic substance for the ointment, the authors conducted a comparative study on the anesthetic effect of the anesthetics most widely available in Ukraine: novocaine, dicainum, lidocaine, trimecainum and pyromecainum. The research conducted on the time it took for the anesthetic effect to occur and on the duration and extent of the effect enabled us to select a $4 \%$ concentration of lidocaine anesthetic for the preparation. The choice of the temperature regime for the ointment's preparation was proved. The in vitro method and rheological studies determined that the optimum temperature regime for the technological process of preparing the ointment on the emulsive base is $25-30{ }^{\circ} \mathrm{C}$. The development and introduction of the new combined ointment on a contemporary hydrophilic ointment base into practical pharmacy would lead to an enlargement in the nomenclature of the medical preparations used for local treatment of the purulent - necrotic phase of the wound process, which is relevant for pharmaceutical technology and global medical science and practice.

Keywords: ofloxacin; nimesulide; lidocaine; rheology; wound process

\section{Introduction}

In the course of the Anti-Terrorist Operation in Ukraine, gunshot and combined wounds dominate in the structure of sanitary casualties among the combatants (around 86.9\%); two thirds of these are limb wounds, combined wounds and head wounds, all of which require urgent and high quality medical treatment, including use of modern highly-efficient wound-healing preparations. Limb wounds which account for 53\% dominate localization of patients' groups, and require urgent elimination of the development of the microflora in the wound, creating optimum conditions for the wound process to develop into the regeneration phase (Cardinal et al., 2009; Healy and Freedman, 2010). Nowadays the practice of treating wounds under dressings makes possible a significant shortening of the systematic antibacterial therapy period, by searching and active introduction of new medical preparations with poly-factor effect and capable of mutually-potentiating and mutually supporting activity, which meet the current requirements 
of pharmaceutical safety and allow efficient local treatment of wounds in accordance with the stage of the wound process (Atiyeh et al., 2009; Hotz et al., 2010). The importance of developing wound-healing preparations with complex effects is conditioned by the increase in the number of post-operational infectious complications, resistance of microorganisms to antibiotics, changes in immune-biological responsiveness of the macroorganism, etc. (Dohmen, 2008; Cardinal et al., 2013).

The search for active substances and adjuvants and methods of technology of production with consideration of physiological peculiarities of the wound surface are the main directions in the development of biopharmaceutics in the sphere of development and enlargement of the nomenclature of domestic soft medical preparations for treatment of the wound process (Owens and Stoessel, 2008; Vyas and Vasconez, 2014). Currently, vulnerary medical preparations are one of the most common pharmaceutical forms. They make up $10 \%$ of the total output of the production of readyto-use formulations. Soft pharmaceutical preparations are used in different spheres of medicine for treatment, diagnosis and prevention of diseases (Swarbrick, 2013). They are characterized by relative simplicity and safety of usage, economical and technological effectiveness (Sheskey et al., 2017). The regulation of pharmaceutical changing factors allows modification of the properties of pharmaceutical ingredients, facilitating their distribution on the wound surface, and prolonging their therapeutic effect, etc. (Swarbrick et al., 2012; Swarbrick, 2013; Farooq et al., 2014; Maitz, 2015). The contact method of implementation of soft pharmaceutical preparations for treating purulent-inflammatory processes allows maximum concentration of the medical substance on the wound area. The method of soft medication introduction is considered the safest, for the greater part of the dose is on the surface of the wounded area (Healy and Freedman, 2010; Rüttermann et al., 2013).

The pharmacotherapeutic effect of medical preparations for treating purulent-inflammatory processes is closely related to the nature, properties and quantitative ratios of the base components. Rationally selected components of the base can increase the therapeutic activity of the active pharmaceutical ingredients, support or impede its release and absorption, increase or decrease its pharmaceutical effect, affect its bioavailability and define various sideeffects, distinguishing the effect of the preparation (resorptive or surface) (Abrantes et al., 2016). The base is essential to the pharmacotherapeutic effect and pharmacokinetics of the preparation. The base impacts the state, properties and the pathological process of the wounded area covered by the soft pharmaceutical preparation. Also, the base determines the consumer properties of the soft pharmaceutical form (Swarbrick, 2013; Chauhan et al., 2016).

Currently, pharmaceutical practice includes around 200 individual and combined ointment and gel bases, which possess different properties and correspond to different medical-biological purposes. There is no perfect base, for provision of the base with required properties involves combining several adjuvants (Maitz, 2015; Chan et al., 2017). As we know, ointments, creams for treating purulent-inflammatory processes, should at the same time possess multi-directional impact on the main etiopathogenetic factors of the inflammation, sufficient osmotic activity, preventing secondary infection (Hotz et al., 2010). Medical usage of the preparation is defined by the usage of the corresponding adjuvants and bases (Merkle, 2015).

In treatment of purulent wounds it is necessary to consider that over the purulent-necrotic phase of the wound process, it is recommended to use soft pharmaceutical forms with a strong antimicrobial, anti-inflammatory, anesthetic and osmolar effect, which are capable of controllable dehydrating activity and impact on the release, bioavailability and therapeutic effect of medical substances (Hotz et al., 2010; Chauhan et al., 2016). It is generally accepted that the manifestation of osmotic activity in anti-inflammatory preparations promotes dehydration in the zone of inflammation, which leads to decrease of edemas and accelerates the metabolic processes in the tissues (Kadajji and Betageri, 2011; Janis and Harrison, 2016).
The substances having these properties are polyethylene oxides of the base (from mixture of macrogols), which due to their bacteriostatic properties are resistant to microbial contamination, and also fully release medical substances and prolong their effectiveness (Maisch, 2007; Kadajji and Betageri, 2011). Bioavailability of the active pharmaceutic ingredients is not related to the temperature of the melting of polyethylene oxidal base and is conditioned only by the speed of dissolution of the bases and their diffusion. From the technological perspective, the advantage of polyethylene oxide (PEO) bases is high viscosity, which prevents the sedimentation of non-dissolved medical substances (Merkle, 2015). Chemical indifference, thermal stability, absence of polymorphic modifications and resistibility to $\mathrm{pH}$ changes determine the suitability of polyethylene oxide bases for production of many pharmaceutical forms for treating purulent-inflammatory processes. The high affinity of the base to biological fluids in the organism (interstitial fluid) facilitates the full release of the active pharmaceutical ingredients from the pharmaceutical form over a certain period of time (Kiamahalleh et al., 2017). Considering the requirements of wound-treatment preparations, the usage of hydrophobic bases is not appropriate, for they minimize the dynamic processes of absorption, and, therefore decrease penetration and release of the medical substances (Merkle, 2015). Modern production of soft pharmaceutical forms for treating purulent-inflammatory processes prefers pharmaceutical preparations on hydrophilic bases, which can be applied to the wound surface without disturbing the perspiration. Active pharmaceutical ingredients are easily absorbed from such substances (Chauhan et al., 2016); non-aqueous solvents in the base, which affect the penetrability of the cellular membranes and increase the absorbability of the preparation, contribute to this process.

Therefore, use of hydrophilic or combined bases which are highly effective in releasing active pharmaceutical ingredients is optimal for developing wound-treatment preparations. This is due to the fact that achieving optimum therapeutic effect in the wounded area requires mixing the base and the medical preparation with exudates of damaged tissues (Healy and Freedman, 2010; Swarbrick, 2013). Pharmaceutical practice uses bases with elasticviscous flexible environment (emulsion of the I generation) and hydrophilic non-aqueous solvents and carbomer gels on the base of hydrophilic surfactants (Haag and Kratz, 2006; Islam et al., 2014). A no less important characteristic of the development of woundtreatment preparations is considered to be the use of I generation emulsion bases (oil/water), which are effective in contacting the wound surface, are capable of a cooling effect due to active evaporation of the water phase of the base, and are able to provide an anesthetic and soothing effect to a certain extent (Debjit et al., 2012; Chauhan et al., 2016).

Thus, considering the abovementioned points and the main stages of pathogenetic wound process development (Atiyeh et al., 2009; Healy and Freedman, 2010), we found it appropriate to include nimesulide, a non-steroidal anti-inflammatory preparation, in the developed ointment (Kopenkin and Talitsky, 2013; Alves et al., 2007); with local usage, this preparation manifests antiinflammatory, anti-edema and local anesthetic effects (Victorov and Kashuba, 2014). The treatment of complex infectious processes of the skin most often uses broad-spectrum antibiotics and antiseptics (Dohmen, 2008; Owens and Stoessel, 2008; Puoci et al., 2012). Therefore, the antibacterial component was ofloxacin, to which a wide range of microorganisms has no resistance (Maisch, 2007). An important part of treatment of the wound process is decreasing the pain threshold. Therefore, for providing the anesthetic effect, lidocaine was added to the new developed medical preparation (Healy and Freedman, 2010; Hotz et al., 2010).

The aim of this article is to present research focused on the scientific grounding and development of a modern Ukrainian-made medical preparation with a complex effect for local treatment of wounds, in the form of an ointment, capable of anti-bacterial, antiinflammatory and local anesthetic effect, and which does not require frequent changes in the treatment of wounded military personnel. 


\section{Materials and methods}

Bacterial strains tested. As cell cultures recommended by the National Pharmacopoeia of Ukraine (Hryzodub et al., 2015), etalon test strains from the American Type Culture Collection were used (USA): Escherichia coli ATCC 10536, Klebsiella pneumoniae ATCC 10031, Pseudomonas aeruginosa ATCC 27853, Candida albicans ATCC 885/653, Proteus vulgaris 4636, Clostridium perfringens A28 (BP6K), Staphylococcus aureus ATCC 25923, Bucillus subtilis ATCC 6633 and strains of the same microorganisms, selected from patients with pathological purulent-inflammatory processes.

Therefore, strains classified as gram-positive and gram-negative, anaerobic and aerobic, sporogenous and non-sporogenous bacteria were selected. The selected microorganisms are considered the main pathogens of purulent-inflammatory process of soft tissues of the epidermis (Trostrup et al., 2013). Among them, the following strains were used: strains of Staphylococcus, Escherichia coli and Pseudomonas aeruginosa, recommended by the World Health Organization. The test strains of bacteria used corresponded to morphological, culture, tinctorial and biochemical properties. As a breeding ground, we used sterile liquid soybean-casein environment ("Biomerieux" Enterprise, France, No 51019).

In the course of the experimental research, the authors used active pharmaceutical ingredients - ofloxacin, nimesulide (gift sample from Dr. Reddy's labs, Hyderabad, India), lidocaine (Merck, Germany), and adjuvants - sodium carboxymethyl cellulose, propylene glycol, eudragit NM30D, glycerine (Loba Chemie Pvt. Ltd., Mumbai, India), polyethylene oxide-400, polyethylene oxide -1500 , dimethyl sulfoxide, sodium cetearyl sulfate, monoglyceryl stearate, cetylstearyl alcohol, polysorbate-80, liquid paraffin (Sigma-Aldrich, Germany). All the chemicals, emulsifiers and reagents were of analytical grade.
Technological, physical-chemical and biopharmaceutical indicators of the ointment were calculated according to the generally accepted methods in accordance with the National Pharmacopoeia of Ukraine (Hryzodub et al., 2015).

Preparation of the model samples. As we know, the highest stability, high dispersity and required viscous-flexible properties of the emulsions are provided by usage of a combination of emulsifiers of the first and the second generation in certain ratios; this defines important data on the inter-phase function of the surfactants (Isaac et al., 2015; Chauhan et al., 2016). It must be acknowledged that emulsions with emulsifiers of different types can be stable at identical values of hydrophilic-lipid balance, which should be distinguished among them (Mastropietro et al., 2013; Islam et al., 2014). The choice of emulsifier considered not only its ability to form stable emulsions with corresponding consistency properties, but also the necessity of providing easy fusion of the ointment with serosal discharges and purulent exudates. For this purpose, to carry out the research in the model samples we used non-ionic surfactants cetylstearyl alcohol for emulsifiers of the first generation, and monoglyceryl stearate as emulsifier of the second generation.

According to data from the literature (Mastropietro et al., 2013), the most frequent optimum concentration of the oil phase in pharmaceutical emulsion ointments is $20 \%$. At this content of oil, it is possible to obtain stable emulsion with satisfactory consumer indicators and viscous-flexible characteristics.

Therefore, in the course of our research, the type of the surfactant was changed, and the following indicators remained constant: total concentration of the surfactant (8\%), and also the content of adjuvants (liquid paraffin - 20\%, polyethylene oxide $-1500-1 \%$, polyethylene oxide $-400-4 \%$, glycerine $-5 \%$, purified water - up to $100 \%)$. For selecting the ointment base, the authors developed 10 model systems (Table 1 ).

Table 1

Model compositions with emulsifiers cetostearyl alcohol and monoglyceryl stearate

\begin{tabular}{|c|c|c|c|c|c|c|}
\hline Model composition & Vaseline oil, \% & Cetostearyl alcohol, \% & Monoglyceryl stearate, \% & Glycerine, \% & PEO-1500 / PEO-400, \% & Purified water up to, $\%$ \\
\hline 1 & 20.00 & 7.75 & 0.25 & 5.00 & $1.00 / 4.00$ & 100.00 \\
\hline 2 & 20.00 & 7.50 & 0.50 & 5.00 & $1.00 / 4.00$ & 100.00 \\
\hline 3 & 20.00 & 7.25 & 0.75 & 5.00 & $1.00 / 4.00$ & 100.00 \\
\hline 4 & 20.00 & 7.00 & 1.00 & 5.00 & $1.00 / 4.00$ & 100.00 \\
\hline 5 & 20.00 & 6.00 & 2.00 & 5.00 & $1.00 / 4.00$ & 100.00 \\
\hline 6 & 20.00 & 5.00 & 3.00 & 5.00 & $1.00 / 4.00$ & 100.00 \\
\hline 7 & 20.00 & 4.00 & 4.00 & 5.00 & $1.00 / 4.00$ & 100.00 \\
\hline 8 & 20.00 & 3.00 & 5.00 & 5.00 & $1.00 / 4.00$ & 100.00 \\
\hline 9 & 20.00 & 2.00 & 6.00 & 5.00 & $1.00 / 4.00$ & 100.00 \\
\hline 10 & 20.00 & 1.00 & 7.00 & 5.00 & $1.00 / 4.00$ & 100.00 \\
\hline
\end{tabular}

Criteria for selecting the base compound. For selecting the base, the authors studied those which are widely used in the pharmaceutical industry and are described in the literature (Table 2).

Osmotic activity was studied at the temperature of $34 \pm 1{ }^{\circ} \mathrm{C}$ in the experiments in vitro using the method of dialysis of semipermeable membrane (Hryzodub et al., 2015). The weighted amount of ointment bases equaled $10 \mathrm{~g}$, the semipermeable membrane defatted intestine. The mass of internal cylinders was weighed 0.5 , 1, 2, 4, 8, 12, 24 hours on AS 220/C Radwag (Poland) analytical scales with up to $0.001 \mathrm{~g}$ accuracy, first wiping them from the external side. As an environment for the dialysis, water was used. The amount of the fluid absorbed by the ointment base was expressed as a percentage in relation to the mass of the studied sample (10 g). The tests were conducted at a temperature of $34 \pm 1^{\circ} \mathrm{C}$ using TS-1/20 SPU Biomed (Kharkiv) thermostat. Periodically, the amount of purified water in the dialysis chamber was adjusted to the initial level. The amount of absorbed amount of fluid was defined according to the difference between two weighings.

Rheological studies were conducted using a RV 2.1 Rheotest rotating viscometer (Germany) according to generally accepted methodic of the National Pharmacopoeia of Ukraine (Hryzodub et al., 2015). The measurements were made at different temperature regimes at speeds of shift from 1.5 to $1332.0 \mathrm{~s}^{-1}$. The thermostatting process was carried out using the ultra thermostat, included in the set of equipment.
Table 2

Model ointment base composition

\begin{tabular}{|c|c|c|c|}
\hline Base No & Ointment base type & Excipients & $\begin{array}{l}\text { The content of } \\
\text { substances, g }\end{array}$ \\
\hline \multirow{5}{*}{1} & \multirow{5}{*}{$\begin{array}{l}\text { Emulsion type oil / } \\
\text { water }\end{array}$} & Vaseline oil & 25.0 \\
\hline & & Tween-80 & 5.0 \\
\hline & & Cetostearyl alcohol & 25.0 \\
\hline & & PEO-400 & 12.0 \\
\hline & & Purified water & 33.0 \\
\hline \multirow{4}{*}{2} & \multirow{4}{*}{$\begin{array}{l}\text { Emulsion type oil / } \\
\text { water }\end{array}$} & Vaseline oil & 10.0 \\
\hline & & PEO-400 & 10.0 \\
\hline & & natrium cetearyl sulfate & 8.0 \\
\hline & & Purified water & 72.0 \\
\hline \multirow{2}{*}{3} & \multirow{2}{*}{ Hydrophilic } & PEO-400 & 80.0 \\
\hline & & PEO-1500 & 20.0 \\
\hline \multirow{3}{*}{4} & \multirow{3}{*}{ Hydrophilic } & eudragit NM30D & 10.0 \\
\hline & & Propylene glycol & 45.0 \\
\hline & & Purified water & 45.0 \\
\hline \multirow{3}{*}{5} & \multirow{3}{*}{ Hydrophilic } & Monoglyceryl stearate & 5.0 \\
\hline & & Glycerin & 10.0 \\
\hline & & Purified water & 85.0 \\
\hline \multirow{3}{*}{6} & \multirow{3}{*}{ Hydrophilic } & Monoglyceryl stearate & 10.0 \\
\hline & & Propylene glycol & 45.0 \\
\hline & & Purified water & 45.0 \\
\hline
\end{tabular}


The tangential stress of shear was calculated using the formula:

$$
\tau_{\mathrm{r}}=\mathrm{Z} \cdot \mathrm{L}
$$

$\tau_{\mathrm{r}}$ - tangential stress of shear $(\mathrm{Pa}), \mathrm{Z}-$ constant of the device (dependency on the type of cylinder), $\mathrm{L}$ - the device's indicator.

After calculating the shear stress at calculated speeds of the shear, we calculated the structural viscosity of the studied samples, using the formula:

$$
\eta=\tau_{\Gamma} / D_{\Gamma}
$$

$\mathrm{D}_{\mathrm{r}}$ - shear speed $\left(\mathrm{s}^{-1}\right), \eta$ - structural viscosity $(\mathrm{Pa} \bullet \mathrm{c}), \tau_{\mathrm{r}}-$ tangential stress of shear $(\mathrm{Pa})$.

The obtained data is necessary for developing rheograms of the ointment's effect. They reflect the relation between the tangential stress of shear $\left(\tau_{\mathrm{r}}\right)$ and shear speed $\left(\mathrm{D}_{\mathrm{r}}\right)$, which is the indicator of the capacity of the ointment to spread. As the control in the study of rheological properties of the developed ointment we used a placebo-ointment (with no pharmaceutical ingredients).

For investigation of the anesthetic properties of local anesthetics we used the device and the method for defining the pain sensitivity, which were developed in the Ukrainian Institute of Improvement of Medical Qualifications (Stefanov et al., 2001).

For determining the anesthetic properties of local anesthetics we used guinea pigs. All animals in the experiments were divided into 6 groups of three. The time when the first subjective feelings, registered with the stopwatch, occurred, was considered the time of beginning of the anesthetic effect. The body of the device was tightly pressed to the studied area of the skin, and the depth of the pain sensitivity was defined by inserting the device's needle with a measurement scale. This depth, defined before applying the anesthetic, was used as the pain threshold. Beginning with the moment of manifestations of the first subjective feelings (the time of the start of the anesthesia), at certain intervals (5-10 min), we defined the depth of the anesthesia by inserting the needle of the device, and considered this as maximum anesthesia. The time during which the needle caused pain was registered as the ending of the anesthetic effect.

The antimicrobial activity of the samples was defined according to the National Pharmacopoeia of Ukraine using the microbiological method of diffusion in agar on a solid growth medium; the method is based on the antibacterial substance's ability to suppress the breeding of bacteria (Hryzodub et al., 2015). The inhibition zones of the breeding of the tested bacteria strains, caused by a tested sample were compared to the diameters of the breeding inhibition zones, which resulted after using the Oflocain referential preparation (Darnytsia Pharmaceutical Enterprise, Ukraine).

Bacterial microorganisms Escherichia coli ATCC 10536, Klebsiella pneumoniae ATCC 10031, Candida albicans ATCC8 85/653, Staphylococcus aureus ATCC 25923, Bucillus subtilis ATCC 6633, Pseudomonas aeruginosa ATCC 27853, Proteus vulgaris 4636, Clostridium perfringens A28 (BP6K) were grown at a temperature of $35{ }^{\circ} \mathrm{C}$ over $18-20$ hours on meat peptone agar. The growth media were examined for sterility and for growth abilities according to the requirements of the National Pharmacopoeia of Ukraine.

Bacterial suspensions were prepared and their optical density was defined at $550 \mathrm{~nm}$ using Densimat BioMerieux densitometer (France) in McFarland units for identifying the concentration of bacterial suspension in colony-forming units (CFU/ml). We selected smooth and uniformly pigmented colonies, which were characterized by growth and tinctorial properties during staining according to Gram's method, then transferred them to a dense growth medium of the same composition and incubated them depending to the species of microorganisms: over 18-20 or 24-48 hours according to anaerobic and aerobic bacteria. In parallel, the number of microorganisms in the suspensions was confirmed using the direct inoculation method on a Petri dish with sterile dense soybeancasein agar growth medium and counted to CFU/ml.

During the next stage of determining the antimicrobial activity of the studied ointment sample, in order to obtain a uniform layer, the corresponding melted agar breeding ground, cooled to 40 $45^{\circ} \mathrm{C}$, was inoculated by test strain in optimum $\left(1 \cdot 10^{7} \mathrm{CFU} / \mathrm{ml}\right)$ concentration and put at $20 \mathrm{ml}$ into Petri dishes, which were situated on the surface of a rotary table, and were left on a smooth horizontal surface until the agar solidified.

Our microbiological studies included the following stages: the prepared suspension $(1 \mathrm{ml})$ with unknown bacterial concentration was put in a prepared API ampoule (with $5 \mathrm{ml}$ of $0.85 \%$ solution of $\mathrm{NaCl}$ ) and mixed; then the ampoule was put in a scanning unit and the numeric McFarland value was calculated. If the obtained value was less than 0.5 , the ampoule was taken out of the device and a necessary amount of bacterial suspension was added. If the amount of the inoculants was higher than 7 , then we dissolved the suspension and repeated the test using another ampoule.

If the obtained value was less than 0.5 , the ampoule was taken out of the device and the required amount of bacterial suspension was added. If the amount of inoculants was higher than 7, then we dissolved the suspension and repeated the test using another ampoule. Each ampoule had to be clean on the outside and wiped before usage. Testing of the device was compulsory: $6 \mathrm{McF}$ arland Standard ampoules with $5 \mathrm{ml}$ in each $(0.5,1,2,3,4,5)$ were in turn put in the densitometer. The test was conducted each time after cleaning the device (Table 3).

\section{Table 3}

Correspondence of McFarland units to optical density

\begin{tabular}{ccc}
\hline McFarland Standard & $\begin{array}{c}\text { Bacterial concentration, } \\
\times 10^{8} \mathrm{ml}^{-1}\end{array}$ & $\begin{array}{c}\text { Theoretical optical } \\
\text { density, 550 nm }\end{array}$ \\
\hline 0.5 & 1.5 & 0.125 \\
1.0 & 3.0 & 0.250 \\
2.0 & 6.0 & 0.500 \\
3.0 & 9.0 & 0.750 \\
4.0 & 12.0 & 1.000 \\
5.0 & 15.0 & 1.250 \\
6.0 & 18.0 & 1.500 \\
7.0 & 21.0 & 1.750 \\
\hline
\end{tabular}

When measuring (to accuracy of $1 \mathrm{~mm}$ ) the zones of strain growth inhibition, we orientated on the zone of full inhibition of visible bacterial growth. The diameters of the growth inhibition zones were measured using a caliper to accuracy of $1 \mathrm{~mm}$ ).

Determining the anti-alternative activity. The biological research were conducted at the Institute of Problems of Pathologies of the National Medical University named after A. A. Bogomolets according to the methodological recommendations (Stefanov et al., 2001) using in vivo method (the model of standard skin wounds) on white rats of 200-240 g body weight. As a comparative preparation, Nimulid (Panacea Biotec Ltd., India) was used.

Under Hexenalum anesthesia, we formed standard skin wounds of $10 \mathrm{~mm}$ diameter and 1.5 to $5.0 \mathrm{~mm}$ depth of scarified wound. First, the skin was depilated and then at the surface a skin wound was inflicted to a standard diameter and depth by a rotating scarificator tightly pressed to the skin. To estimate anti-alternative activity we used an indicator of area (S) of the wound $\left(\mathrm{mm}^{2}\right)$, which was measured planimetrically. This indicator was used for calculation of the percentage of the activity of the tested preparation in relation to non-treated animals.

The speed of healing of wounds was calculated using the formula:

$$
\mathrm{V}=\frac{\mathrm{S}_{\mathrm{y}}-\mathrm{S}_{\mathrm{t}}}{\mathrm{S}_{\mathrm{y}}} \cdot 100
$$

$\mathrm{V}$ - speed of wound healing (\%), $\mathrm{S}_{\mathrm{y}}$ - initial wound area $\left(\mathrm{mm}^{2}\right)$, $\mathrm{S}_{\mathrm{t}}$ - wound area in the day of measurement $\left(\mathrm{mm}^{2}\right)$.

To the compound of the pharmaceutical form, nimesulid was added in a form of a solution in dimethyl sulfoxide concentration from $0.5 \%$ to $1.0 \%$ (Table 4 ).

Studying the impact of the method of introducing the active pharmaceutical ingredients to the ointment compound and their antibacterial properties with further determination of their optimum concentration. Considering the physical-chemical properties of the active pharmaceutical ingredients, ofloxacin and nimesulide were introduced as solution in dimethyl sulfoxide, suspension with polyethylene oxide - 400, glycerine and liquid paraffin. Lidocaine is easily soluble in water and hydrophilic non- 
aqueous solvents, therefore, it was introduced to the ointment base in the form of solution in water, solution in dimethyl sulfoxide and solution in polyethylene oxide - 400 (Davtian, 2009).

Table 4

Concentration of active pharmaceutical ingredient in the ointment developed to treat groups of animals

\begin{tabular}{ccccc}
\hline \multirow{2}{*}{$\begin{array}{c}\text { Group of } \\
\text { animals }\end{array}$} & Drug/composition & \multicolumn{2}{c}{$\begin{array}{c}\text { Concentration of active } \\
\text { pharmaceutical ingredient }\end{array}$} \\
\cline { 4 - 5 } & & & Ofloxacin & Nimesulide \\
\hline 1 & \multicolumn{2}{c}{-} & - & - \\
\hline 2 & Preparation of & Oflocaxin & - & - \\
3 & comparison & Nimulid & - & 1.0 \\
\hline 4 & & 1a & 0.10 & 1.0 \\
5 & Ointment & 1b & 0.05 & 0.5 \\
6 & & 1c & 0.05 & 1.0 \\
\hline
\end{tabular}

The research was conducted in five series (five samples in each). Statistical analysis of the obtained results were made using Statistica 6.0 (StatSoft Inc., USA). Data in the tables was provided as $\mathrm{x} \pm \mathrm{SE}$, where $\mathrm{x}$ is average value of the indicator, SE is standard deviation. The results were considered statistically reliable at $\mathrm{P}<$ 0.05 (Mincer et al., 2003).

\section{Results}

Proving the selection of the base compound. The development of the compound and the technology of the soft pharmaceutical preparation were based on current medical-biological requirements for wound-treating preparations, developed on emulsion and hydrophilic bases.

Research on the osmotic properties of the model samples of the base. As we know, the process of release of active pharmaceutical ingredients from ointments is closely related to the osmotic activity of the bases. This factor is considered a treatment factor, which decreases edema and facilitates dehydration in the inflammatory zone, and provides necessary conditions for healing of damaged surface of skin. As an environment for dialysis, water was used. The obtained data was presented as a curve of dependency of the liquid absorption upon the duration of dialysis (the numbers of the curves correspond to the numbers of model bases). The authors conducted studies on osmotic activity of the model bases (Fig. 1).

The results of the research conducted showed that the highest osmotic activity $-280.0 \pm 1.5 \%$ was shown by the sample of the ointment base 3, which was developed on a polyethylene oxide base. The ointment bases 1 and 2 showed similar osmotic properties (180.0 \pm
$0.35 \%, 175.2 \pm 0.23 \%$ respectively). Moderately higher osmotic properties were observed in the samples of the ointment bases 5 and 6 ( $230.3 \pm 0.24 \%, 250.2 \pm 0.36 \%$ respectively). Considering the medicalbiological requirements to the pharmaceutical formulations for treating phase one of the wound process, in particular high osmotic activity, which would provide a contributory effect on cleansing purulent exudates of wounds, we chose the base 3, which includes alloy of PEO-400 and PEO-1500 (4: 1), for further tests.

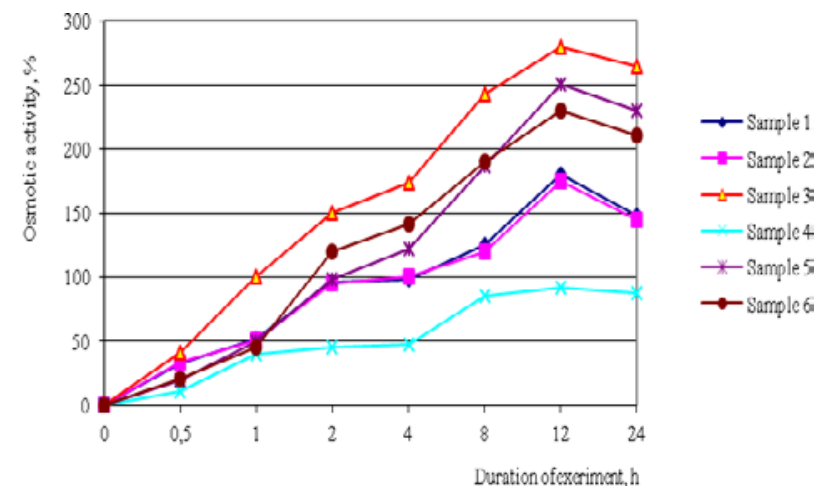

Fig. 1. Osmotic activity of model samples

Proving the choice of the emulsifiers for stabilizers of hydrophilic base. During the process of selecting the emulsifiers for stabilizing the emulsion, we studied the dependency of the rheological indicators of the emulsions on the type, ratio and the number of emulsifiers of the first and the second generation. For calculating the ratios of the emulsifiers, we constructed full rheograms of the activities of the model bases in the following coordinates: the speed of shear $\left(\mathrm{Dr}, \mathrm{c}^{-1}\right)-$ the shear stress ( $\tau$ r, Pa) (Fig. 2, 3). The numbers of the curves correspond to the numbers of the model bases.

As a result of the research, we chose for the development of a combined ointment model composition 6 with the following compound of the emulsifiers: 5.0\% cetylstearyl alcohol and 3.0\% monoglyceryl stearate. This studied sample possesses the best thixotropic properties, which can be seen in the significant surface of area between the upward and downward curves, which indicates that it is capable of dissolving after being applied to the skin, is easily applied and is capable of extrusion from the tubes; also the consistency of the ointment base is satisfactory, for the stress curves are fully included in the area of optimum rheology of $\mathrm{AB}$ and $\mathrm{CD}$ for hydrophilic ointments.

$$
D_{r}, s^{-1}
$$

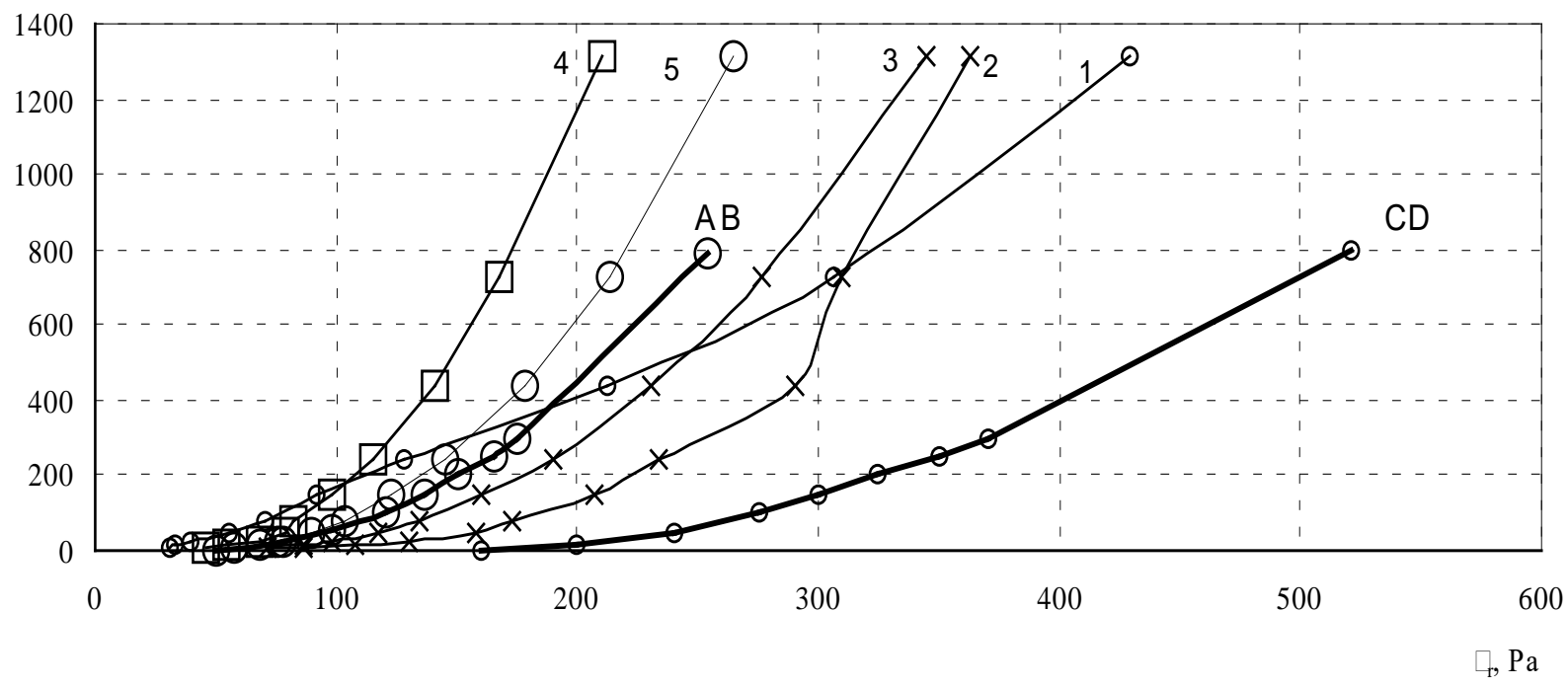

Fig. 2. Rheogram of model compositions flow with emulsifiers, cetostearyl alcohol / monoglyceryl stearate: 1. - 7.75\% / 0.25\%, 2. - (7.5\% / 0.5\%), 3. - (7.25\% / 0.75\%), 4. - (7.0\% / 1.0\%), 5. - (6.0\% / 2.0\%); AB and CD - borders of the rheological optimum in consistencies 


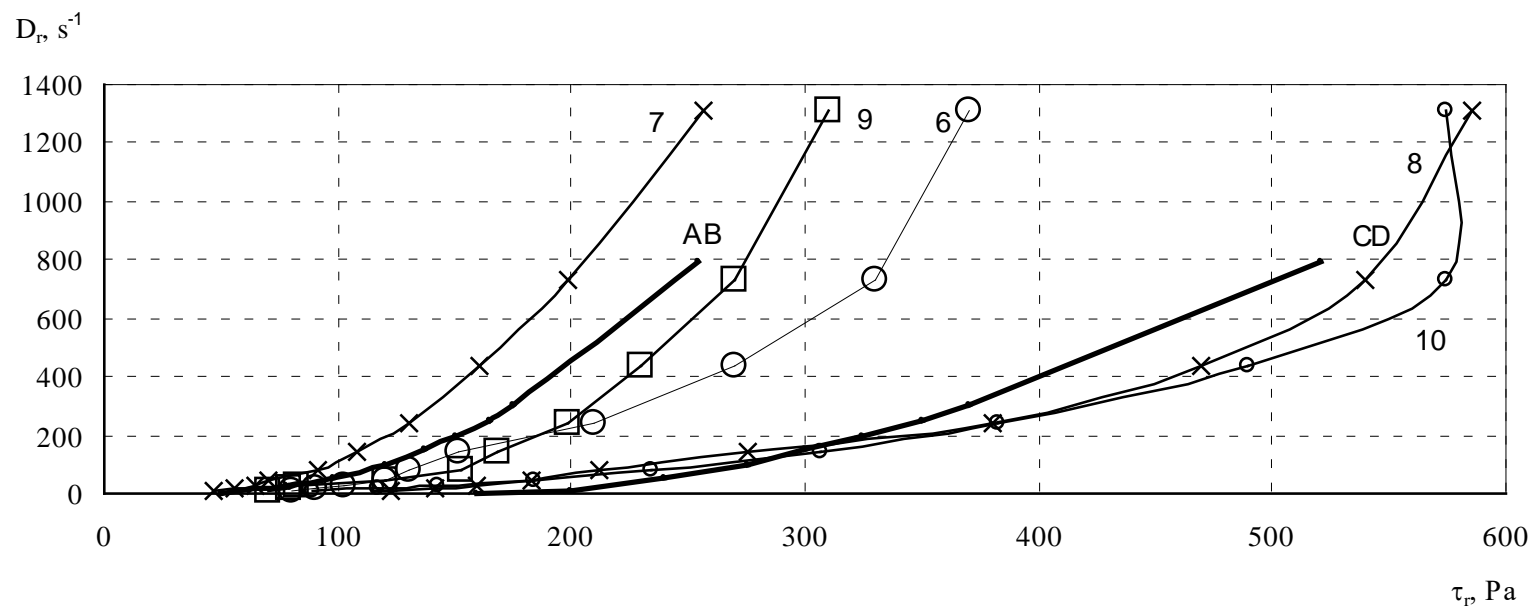

Fig. 3. Rheogram of model compositions flow with emulsifiers, cetostearyl alcohol / monoglyceryl stearate: 6. - (3.0\% / 5.0\%), 7. - (4.0\% / 4.0\%), 8. - (5.0\% / 3.0\%), 9. - (2.0\% / 6.0\%), 10. - (1.0\% / 7.0\%); AB and CD - borders of the rheological optimum in consistencies

Proving the selection of the hydrophilic non-aqueous solvents for the ointment compound. The next stage of research was proving the introduction of a certain amount of glycerine to the ointment compound by finding out the impact of this substance at various concentrations on the osmotic properties of emulsion ointment systems. According to the data from the literature, most soft pharmaceutical forms are provided with moisturizing and softening properties through addition of glycerine at concentrations ranging from $2.0 \%$ to $10.0 \%$. It serves as a penetrant and solubilizer and is capable of increasing the transepidermal penetration of water and other substances.

On the basis of previous research into of the impact of glycerine concentration on osmotic properties of emulsion ointment systems, we researched the emulsion model ointment base 6 with a combination of the emulsifiers of cetylstearyl alcohol and monoglyceryl stearate in ratios of $5 \%$ and $3 \%$ respectively, with glycerine content up to $10 \%$. The non-aqueous solvent was introduced to the prepared emulsion at a temperature of $40 \pm 2{ }^{\circ} \mathrm{C}$. For deciding the quantitative compound of the osmotically active solvent in the composition of the ointment base, we chose glycerine at different concentrations (2.5\%, 5.0\%, 7.5\% and 10.0\%) and researched its osmotic activity (Fig. 4).

The conducted studies showed that the model samples 1,3 and 4 manifested significant osmotic properties after 12 hours (160.0 $\pm 2.7 \%$, $170.2 \pm 2.5 \%, 165.2 \pm 2.1 \%$ respectively). The sample 2 significantly differed in absorption properties (195.5 $\pm 2.7 \%)$. Such high percentage of the indicator of osmotic activity facilitates elimination of purulent discharges from the damaged tissues, causing anti-inflammatory activity and providing a prolonged and mild dehydrating effect.

Determining the optimum concentration of ofloxacin using in vitro method. For determining the optimum concentration of ofloxacin in the ointment compound, we added it at $0.025 \%$ to $0.100 \%$ concentrations with a two step increase. The comparative analysis of the obtained experimental data (in vitro method) showed that the optimum concentration of ofloxacin in the ointment compound is $0.05 \%$. At such concentration, the diameters of the zones of growth inhibition of the strains equaled $26.0 \pm 0.33 \mathrm{~mm}$ for $E$. coli, $26.9 \pm 0.22 \mathrm{~mm}$ for $K$. pneumoniae, $26.3 \pm 0.11 \mathrm{~mm}$ for $S$. aureus, $26.3 \pm 0.11 \mathrm{~mm}$ for $C$. perfringens, $26.7 \pm$ $0.20 \mathrm{~mm}$ for $C$. albicans, $30.5 \pm 0.23 \mathrm{~mm}$ for $P$. aeruginosa and $30.2 \pm$ $0.33 \mathrm{~mm}$ for $P$. vulgaris respectively. For more accurate determination of the optimum ofloxacin concentration in the ointment, we studied antibacterial activity of samples with ofloxacin content within the range $0.03 \%$ to $0.10 \%$ (Table 5 ).

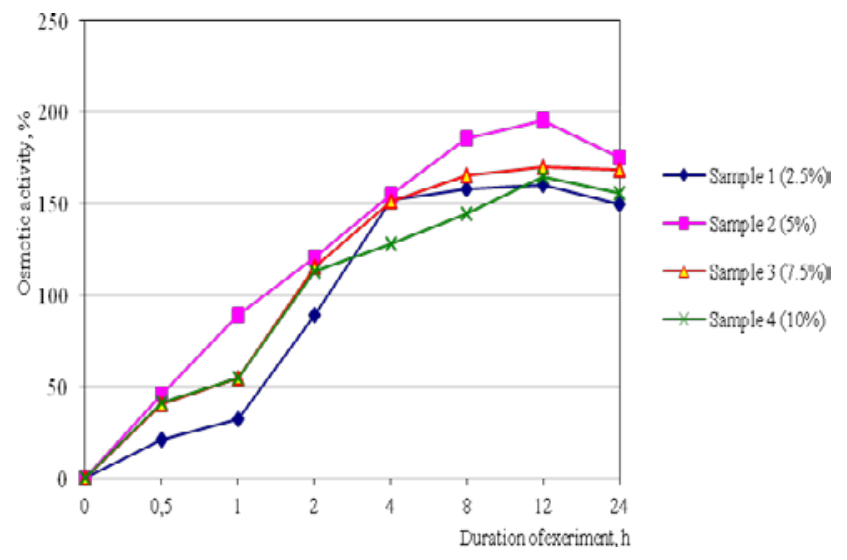

Fig. 4. Dependence of osmotic properties of model emulsion ointment bases on concentrations of glycerol

The obtained results showed that further increase of the ofloxacin concentration caused gradual decrease in the zones of inhibition of strain growth, i.e. to $25.0 \pm 0.11 \mathrm{~mm}$ for $E$. coli, to $24.7 \pm 0.12 \mathrm{~mm}$ for $K$. pneumoniae, to $24.8 \pm 0.12 \mathrm{~mm}$ for $S$. aureus, to $26.4 \pm 0.32 \mathrm{~mm}$ for C. perfringens, to $24.6 \pm 0.31 \mathrm{~mm}$ for $C$. albicans to $27.0 \pm 0.12 \mathrm{~mm}$ for $P$. aeruginosa and to $27.0 \pm 0.30 \mathrm{~mm}$ for $P$. vulgaris respectively. Therefore, the optimum ofloxacin concentration for the ointment proved to be $0.05 \%$.

\section{Table 5}

Ointment antimicrobial activity at different ofloxacin concentrations $\left(10^{7} \mathrm{CFU} / \mathrm{ml}\right.$ in the top layer of the growth medium, $\left.\mathrm{x} \pm \mathrm{SE}\right)$

\begin{tabular}{|c|c|c|c|c|c|c|c|}
\hline \multirow[b]{2}{*}{$\begin{array}{c}\text { Ofloxacin } \\
\text { concentration, \% }\end{array}$} & \multicolumn{7}{|c|}{ Diameter of the test strain growth inhibition zone, mm } \\
\hline & $\begin{array}{c}\text { E. coli } \\
\text { ATCC } 10536\end{array}$ & $\begin{array}{c}\text { K. pneumoniae } \\
\text { ATCC } 10031\end{array}$ & $\begin{array}{c}\text { S. aureus } \\
\text { ATCC } 25923\end{array}$ & $\begin{array}{l}\text { C. perfringens } \\
\text { A28 (BP6K) }\end{array}$ & $\begin{array}{c}\text { C. albicans } \\
\text { ATCC8 85/653 }\end{array}$ & $\begin{array}{l}\text { P. aeruginosa } \\
\text { ATCC } 27853\end{array}$ & $\begin{array}{c}\text { P. vulgaris } \\
4636\end{array}$ \\
\hline 0.03 & $23.1 \pm 0.12$ & $26,3 \pm 0.12$ & $25.3 \pm 0.12$ & $27.0 \pm 0.20$ & $26.5 \pm 0.10$ & $28.4 \pm 0.21$ & $29.3 \pm 0.22$ \\
\hline 0.04 & $24.4 \pm 0.22$ & $26.4 \pm 0.13$ & $26.4 \pm 0.12$ & $27.6 \pm 0.17$ & $27.1 \pm 0.10$ & $29.2 \pm 0.12$ & $29.1 \pm 0.13$ \\
\hline 0.05 & $26.0 \pm 0.33$ & $26.9 \pm 0.22$ & $26.3 \pm 0.11$ & $28.2 \pm 0.14$ & $26.7 \pm 0.20$ & $30.5 \pm 0.23$ & $30.2 \pm 0.33$ \\
\hline 0.06 & $25.2 \pm 0.22$ & $26.5 \pm 0.23$ & $25.5 \pm 0.22$ & $27.7 \pm 0.24$ & $25.8 \pm 0.20$ & $30.0 \pm 0.14$ & $29.0 \pm 0.10$ \\
\hline 0.07 & $25.2 \pm 0.33$ & $25.2 \pm 0.11$ & $25.1 \pm 0.13$ & $27.3 \pm 0.14$ & $25.2 \pm 0.20$ & $30.0 \pm 0.32$ & $28.7 \pm 0.11$ \\
\hline 0.08 & $25.2 \pm 0.22$ & $25.1 \pm 0.31$ & $25.0 \pm 0.31$ & $27.1 \pm 0.31$ & $25.1 \pm 0.10$ & $28.3 \pm 0.12$ & $28.3 \pm 0.20$ \\
\hline 0.09 & $25.1 \pm 0.22$ & $25.1 \pm 0.12$ & $25.0 \pm 0.13$ & $26.8 \pm 0.14$ & $25.0 \pm 0.10$ & $28.0 \pm 0.24$ & $27.4 \pm 0.12$ \\
\hline 0.10 & $25.0 \pm 0.11$ & $24.7 \pm 0.12$ & $24.8 \pm 0.12$ & $26.4 \pm 0.32$ & $24.6 \pm 0.31$ & $27.0 \pm 0.12$ & $27.0 \pm 0.30$ \\
\hline
\end{tabular}


Determining the anti-alternative activity for identifying the optimum nimesulide concentration. The model of standard skin wounds of rats is the most common method for defining specific anti-alternative activity, which enables observation of the medical effect of a preparation at alternative inflammations and its impact on wound healing. The advantage of this method is standard conditions of wound formation. For the experiments on the animals we received permission from bioethical experts. All animals in the study were divided into six groups of six animals each (Table 6). Analysis of the data in Table 6 showed that from the 5th day of the experiment, the area of ulcers among animals of all groups began to significantly decrease. Active reduction of the ulcer areas among the animals and occurrence of juicy granulations in the wounds indicated the transition from phase I of the wound process to phase II - granulation and proliferation. A certain regularity was observed: treatment with compositions with a concentration of ofloxacin and nimesulide at $0.05 \%$ and $0.50 \%$ respectively ( $1 \mathrm{~b}$ ) was longer compared to the compositions 1a and 1c. Considering the almost identical pharmaceutical effect on the organism of animals at different concentrations of the active pharmaceutical ingredients, we chose their optimum concentrations for the ointment compound: $0.05 \%$ of ofloxacin and $1.00 \%$ of nimesulide.

Table 6

Planimetric figures for ointments and drugs compared to models aseptic skin ulcers in rats, $\mathrm{x} \pm \mathrm{SE}, \mathrm{P}<0.05$

\begin{tabular}{|c|c|c|c|c|c|c|c|}
\hline Day of treatment & Indicator & Control pathology & Ofloxacin, $0.1 \%$ & Nimesulid, $1.0 \%$ & $1 \mathrm{a}$ & $1 \mathrm{~b}$ & 1c \\
\hline 1 & aseptic area of ulcers (S) & 1.08 & 1.09 & 1.03 & $1.03^{* *}$ & $1.02^{* *}$ & $1.04 * *$ \\
\hline \multirow{2}{*}{3} & aseptic area ulcers (S) & 0.89 & 0.92 & 0.93 & $0.92^{* * *}$ & $0.89^{* *}$ & $0.87^{* *}$ \\
\hline & speed of wound healing (V) & 4 & 6 & 13 & $12 *$ & 9* & $17^{*}$ \\
\hline \multirow{2}{*}{5} & aseptic area of ulcers (S) & 0.87 & 0.89 & 0.62 & $0.60 * *$ & $0.71^{* *}$ & $0.61^{* *}$ \\
\hline & speed of wound healing (V) & 13 & 16 & 39 & $43 *$ & $35 *$ & $47^{*}$ \\
\hline \multirow{2}{*}{7} & aseptic area of ulcers (S) & 0.79 & 0.83 & 0.45 & $0.4^{* *}$ & $0.29 * *$ & $0.31^{* *}$ \\
\hline & speed of wound healing (V) & 23 & 19 & 58 & $73 *$ & $68 *$ & $74^{*}$ \\
\hline \multirow{2}{*}{9} & aseptic area of ulcers (S) & 0.66 & 0.74 & 0.25 & $0.15^{* *}$ & $0.18^{* *}$ & $0.14^{* *}$ \\
\hline & speed of wound healing (V) & 35 & 28 & 79 & $86 *$ & $85 *$ & $88 *$ \\
\hline \multirow{2}{*}{11} & aseptic area of ulcers (S) & 0.57 & 0.55 & 0.18 & $0.07 * *$ & $0.09 * *$ & $0.04 * *$ \\
\hline & speed of wound healing $(\mathrm{V})$ & 44 & 47 & 83 & $100^{*}$ & $93 *$ & $100 *$ \\
\hline \multirow{2}{*}{13} & aseptic area of ulcers (S) & 0.42 & 0.28 & 0.10 & - & $0.02^{* *}$ & - \\
\hline & speed of wound healing (V) & 58 & 65 & 90 & - & $100 *$ & - \\
\hline \multirow{2}{*}{15} & aseptic area of ulcers (S) & 0.35 & 0.16 & 0.06 & - & - & - \\
\hline & speed of wound healing $(\mathrm{V})$ & 63 & 76 & 92 & - & - & - \\
\hline
\end{tabular}

Note: $\mathrm{S}$ - aseptic area of ulcers $\left(\mathrm{mm}^{2}\right), \mathrm{V}$ - speed of wound healing $(\%), *$ - researched drug activity relative to control pathology, ** - researched drug activity relative to Ofloxacin and Nimesulid.

Selection of anesthetic medical substance in the ointment compound. We conducted a comparative study on the anesthetic effect of the most common domestic anesthetics: novocaine, dicainum, lidocaine, trimecainum and pyromecainum at concentrations from $1 \%$ to $10 \%$. We determined the time of the beginning, duration and depth of the anesthesia. The experiments established that when lidocaine was used, the anesthesia began 5-20 min earlier than with solutions of other anesthetics at the same concentrations. Lidocaine showed the longest duration of anesthesia (20-50 min). At the moment of the maximum anesthesia, its depth when lidocaine was used equaled $0.4-0.7 \mathrm{~mm}$. Therefore, the concentration of lidocaine of $4 \%$ was proven by the experimental studies.

Research on the impact of the method of introducing active pharmaceutical ingredients to the ointment composition and their antibacterial activity. The microbiological experiments proved the usefulness of introduction of active pharmaceutical ingredients in the form of solution in dimethyl sulfoxide (Table 7). Examination of the zones of inhibition of strain growth in relation to E. coli, K. pneumoniae, C. albicans, $S$. aureus, B. subtilis and $P$. aeruginosa showed that the solution of ofloxacin and nimesulide in dimethyl sulfoxide manifested higher antibacterial activity. The comparative analysis of the experimental results showed that the samples of ointment in which lidocaine was introduced to the base as a solution in dimethyl sulfoxide also manifested significant antibacterial activity, which equaled $22.2 \pm 0.2$, $23.0 \pm 0.5,22.9 \pm 0.7,22.2 \pm 0.5,22.2 \pm 0.5$ and $22.2 \pm 0.5 \mathrm{~mm}$ and E. coli, K. pneumoniae, C. albicans, S. aureus, B. subtilis and P. aeruginosa respectively.

Table 7

Indicators of antibacterial activity of the ointment samples with different methods of introducing active pharmaceutical ingredients ( \pm SE)

\begin{tabular}{|c|c|c|c|c|c|c|c|}
\hline & \multirow[b]{2}{*}{ Model samples } & \multicolumn{6}{|c|}{ Microorganisms inhibition growth zones, mm } \\
\hline & & $\begin{array}{c}\text { E. coli } \\
\text { ATCC } 10536\end{array}$ & $\begin{array}{c}\text { K. pneumoniae } \\
\text { ATCC } 10031\end{array}$ & $\begin{array}{c}\text { C. albicans } \\
\text { ATCC8 85/653 }\end{array}$ & $\begin{array}{c}\text { S. aureus } \\
\text { ATCC } 25923\end{array}$ & $\begin{array}{c}\text { B. subtilis } \\
\text { ATCC } 6633\end{array}$ & $\begin{array}{l}\text { P. aeruginosa } \\
\text { ATCC } 27853\end{array}$ \\
\hline \multirow{4}{*}{$\begin{array}{l}\text { Ofloxacin / } \\
\text { Nimesulide }\end{array}$} & Solution in dimethylsulfoxide & $24.8 \pm 0.21$ & $24.2 \pm 0.50$ & $23.4 \pm 0.21$ & $24.0 \pm 0.20$ & $23.3 \pm 0.30$ & $24.5 \pm 0.31$ \\
\hline & Suspension of PEO-400 & $22.4 \pm 0.11$ & $21.4 \pm 0.32$ & $21.3 \pm 0.32$ & $22.2 \pm 0.32$ & $21.3 \pm 0.61$ & $22.5 \pm 0.30$ \\
\hline & Suspension of glycerol & $18.2 \pm 0.52$ & $19.1 \pm 0.41$ & $18.6 \pm 0.21$ & $19.2 \pm 0.44$ & $19.2 \pm 0.22$ & $19.2 \pm 0.40$ \\
\hline & The suspension of vaseline oil & $20.2 \pm 0.34$ & $21.1 \pm 0.31$ & $22.2 \pm 0.31$ & $20.1 \pm 0.22$ & $20.1 \pm 0.11$ & $23.6 \pm 0.31$ \\
\hline \multirow{3}{*}{ Lidocaine } & Solution in water & $20.1 \pm 0.53$ & $19.9 \pm 0.21$ & $19.3 \pm 0.31$ & $19.5 \pm 0.44$ & $19.9 \pm 0.62$ & $19.4 \pm 0.52$ \\
\hline & Solution in dimethylsulfoxide & $22.3 \pm 0.22$ & $23.0 \pm 0.21$ & $22.9 \pm 0.21$ & $22.2 \pm 0.55$ & $22.2 \pm 0.52$ & $22.2 \pm 0.62$ \\
\hline & Solution to the PEO-400 & $16.6 \pm 0.64$ & $17.2 \pm 0.33$ & $18.1 \pm 0.21$ & $17.6 \pm 0.21$ & $17.3 \pm 1.10$ & $19.1 \pm 0.75$ \\
\hline
\end{tabular}

Proving the choice of temperature regime in the technology of producing the ointment. To research the optimum temperature regime for making of the ointment, the authors examined the impact of the temperature factor on the antimicrobial activity of the ointment. For this purpose, samples of the ointment were studied at the following temperature regimes: $20-30,30-40$ and $40-50{ }^{\circ} \mathrm{C}$ (Table 8). At temperatures of $20-30$ and $30-40{ }^{\circ} \mathrm{C}$ the samples manifested approximately identical bactericidal effects on the strains, therefore the optimum temperature regime for introducing active pharmaceutical ingredients to the ointment base is temperatures up to $40^{\circ} \mathrm{C}\left(30-40^{\circ} \mathrm{C}\right)$.

Further studies on rheological properties of the ointment including ofloxacin, nimesulide and lidocaine (Fig. 5) showed that maximum decomposition of systems occurs at the temperature of $40^{\circ} \mathrm{C}$. The analysis of the hysteresis loops at different temperatures (Fig. 5 and 6) suggests the conclusion that the studied ointment sample was capable of sufficient thixotropy, which was also indicated by significant areas of hysteresis at the temperatures of 25 and $30^{\circ} \mathrm{C}$.

The character of the rheograms indicates that an increase in the shear speed causes directly proportional dependency of the stress on the speed of deformation, which also indicates the relationship of the ointment to viscous-flexible bodies with a certain structure. Thus, the in vitro method and rheological studies proved that the optimum temperature regime for the technological process equals $25-30^{\circ} \mathrm{C}$. Therefore, the conclusion can be drawn that the studied system has clearly manifested thixotropic properties, which may be indicated by the significant area between upward and downward curve. The thixotropic properties 
of the ointment indicate its sufficient ability to spread and to be extruded from tubes. At high temperatures, on one hand, the decomposition of the system occurs, and, on the other hand, its spreading and extrusion from the tubes becomes easier. To prevent decomposition of the system, the ointment should be maintained at room temperature.

Research on the structural-mechanical properties of the developed ointment. For a fuller and more objective evaluation of the consumer properties of the developed ointment, particularly its ability to spread, we conducted experiments on defining the stress shear within the range of 125-275 s ${ }^{-1}$ speeds, when the ability of an ointment to cover the skin is modeled. A sample of the ointment was put in a graduated cylinder of a viscosimeter, which was thermostatted at a temperature of $34^{\circ} \mathrm{C}$; then we studied the shear stress at two speeds: 145 and $243 \mathrm{~s}^{-1}$. Each shear speed test was made using a separate covering of the ointment. The indicators of the viscosometer scale were registered 2-3 s after it was turned on and $15 \mathrm{~s}$ after the device's operation. The results showed that the spreading capacity of the ointment was satisfactory the limited rheogram fully fits the area of the optimum for rheology of the distinguished polygon ABVGDEKLM (Fig. 7). Thus, on the basis of the obtained results, the conclusion can be drawn that the studied ointment has sufficient thixotropy, which means that it is capable of dissolving while being spread on the skin, covers the skin well and is capable of extrusion from the tubes; also the consistency of the ointment and ointment base is satisfactory for the shear stress curves fully fit the area of the optimum for hydrophilic ointments.

\section{Table 8}

Effect of temperature on the antimicrobial activity of ointment $(x \pm S E)$

\begin{tabular}{lccc}
\hline \multirow{2}{*}{ Microorganism } & \multicolumn{3}{c}{ Temperature, ${ }^{\circ} \mathrm{C}$} \\
\cline { 2 - 4 } & $20-30$ & $30-40$ & $40-50$ \\
\hline Candida albicans ATCC8 85/653 & $20.4 \pm 0.51$ & $19.1 \pm 0.52$ & $15.9 \pm 0.22$ \\
Klebsiella pneumoniae ATCC 10031 & $20.2 \pm 0.22$ & $19.0 \pm 0.33$ & $16.0 \pm 0.41$ \\
Escherichia coli ATCC 10536 & $21.6 \pm 0.33$ & $20.3 \pm 0.21$ & $18.1 \pm 0.32$ \\
Bacillus subtilis ATCC 6633 & $19.6 \pm 0.51$ & $19.2 \pm 0.42$ & $17.3 \pm 0.33$ \\
Clostridium perfringens A28 (BP6K) & $21.0 \pm 0.42$ & $20.1 \pm 0.31$ & $16.2 \pm 0.22$ \\
Staphylococcus aureus ATCC 25923 & $19.2 \pm 0.20$ & $19.6 \pm 0.21$ & $15.2 \pm 0.50$ \\
Pseudomonas aeruginosa ATCC 27853 & $20.1 \pm 0.61$ & $20.0 \pm 0.52$ & $16.0 \pm 0.51$ \\
Proteus vulgaris ATCC 4636 & $20.2 \pm 0.50$ & $20.2 \pm 0.61$ & $15.0 \pm 0.60$ \\
\hline
\end{tabular}

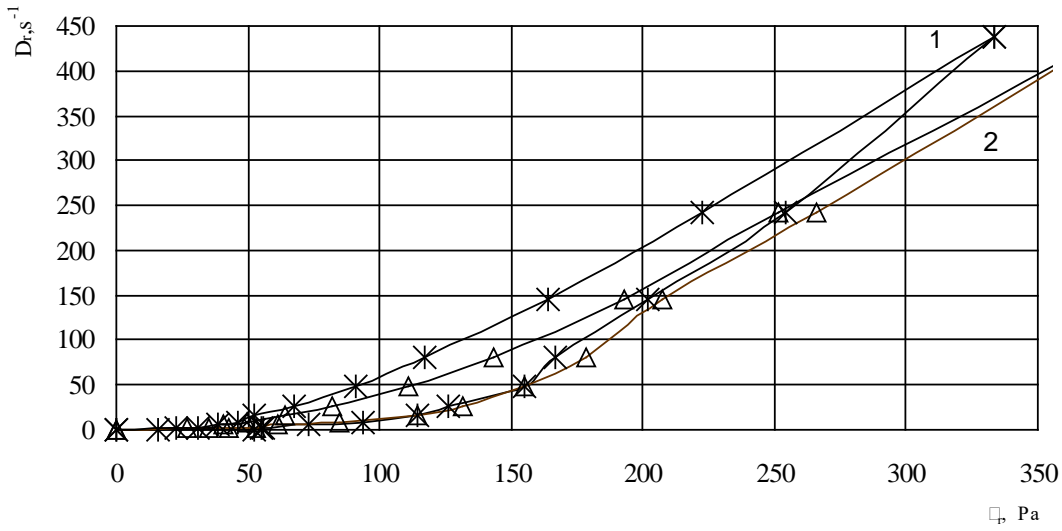

Fig. 5. Rheogram of ointment at different temperatures: $1-25^{\circ} \mathrm{C} ; 2-30^{\circ} \mathrm{C}$

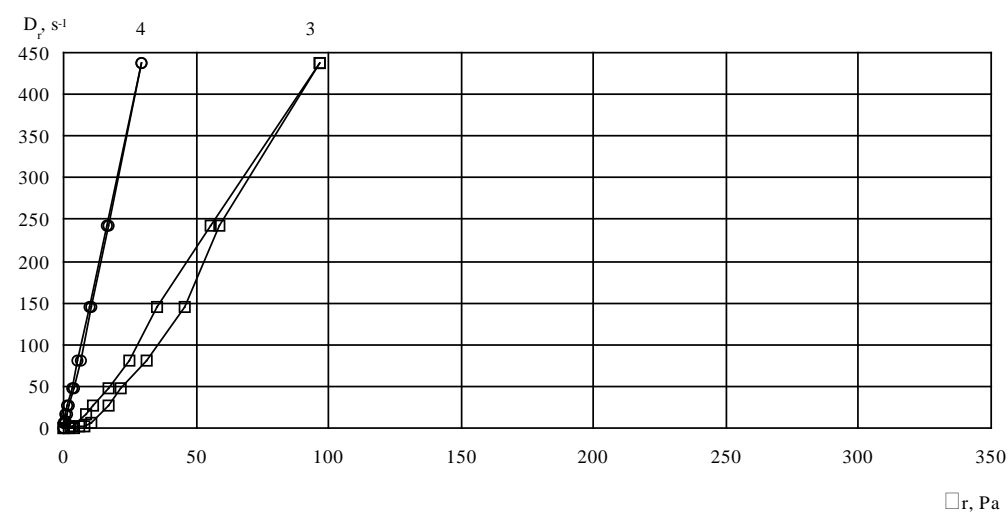

Fig. 6. Rheogram of ointment at different temperatures: $3-37^{\circ} \mathrm{C} ; 4-40^{\circ} \mathrm{C}$

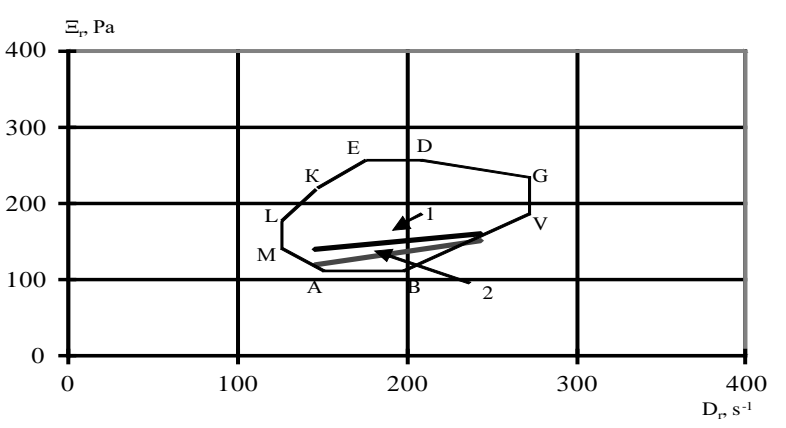

Fig. 7. Area distinguished by rheograms of effect of the ointment at $34^{\circ} \mathrm{C}: 1-$ after $2-3 \mathrm{~s} ; 2-$ after $15 \mathrm{~s}$

\section{Discussion}

Proving the composition of the base's compound. Recent biopharmaceutical studies on pharmaceutical preparations of local application have shown that with a well reasoned selection of the base, it is possible to provide a strong and sometimes intensified effect of the medical substances included in the compound. The authors (Rudenko, 2013; Trostrup et al., 2013) introduced new polyethylene-based ointments (combinations of polyethylene oxides with molecular weight of 400 and 1500) into clinical practice. Polyethylene oxides are of low toxicity and express clearly visible osmotic properties (Farooq et al., 2014).

Kadajji and Betageri (2011) and Merkle (2015) emphasize that polyethylene-based combined ointments are highly promising, being different from traditional preparations due, first of all, to their multidirec- 
tional effect. In particular, these preparations allow management of the intensity and the direction of the diffusion process after applying the formulation to the wound for differential usage at different stages of the wound process. The authors consider (Owens and Stoessel, 2008; Rüttermann, 2013) that intensified efficiency of the prevention and treatment of the infectious complications in wounds is currently impossible without radically new combined ointments on modern bases, which include highly efficient antibacterial preparations: Levomycetin (Levosin, Levomecol), Dioxydin (5\% Dioxydin ointment, Dioxycolum), Nltazolum (Nitacid) (Maisch, 2007; Barajas-Nava et al., 2013). Also, the new ointments include such preparations as trimecaine hydrochloride for providing an anesthetic effect of the ointment and methyluracil, which is capable of anabolic and anti-catabolic activity for stimulating processes of cell regeneration (Atiyeh et al., 2009; Nishio and Suzuki, 2009). In our research, for achieving optimum pharmaceutical effect, particularly antibacterial, anti-inflammatory, and analgesic effects, the compound of the studied ointment included active pharmaceutical ingredients, which are commonly used and which proved to work well in dermatological and surgical practice: ofloxacin, nimesulide, lidocaine (Barajas-Nava et al., 2013; Victorov and Kashuba, 2014).

Analysis of the osmotic properties of model samples of the bases. Maisch (2007) determined the goals of pharmacotherapy in the first phase of the wound process: decreasing inflammatory reactions (skin edemas, transudation, and painfulness), providing antibacterial protection of the wound and cleaning necrotic formations from the wound. Over recent years, we have seen a tendency towards more optimum usage of ointments, considering not only their pharmacotherapy characteristics, but also other indicators: the type of base, $\mathrm{pH}$, dispersity, osmotic properties, etc. The authors (Rudenko et al., 2013; Swarbrick, 2013) described medical-biological requirements to ointments, including osmotic activity. Manifestation of high osmotic activity of anti-inflammatory and antibacterial preparations is considered to provide intense outflow of exudates from the depth of the wound onto the bandage, rejecting and melting of the necrotic tissues and evacuation of the wound contents, and also contributes to dehydration in the inflammatory zone, which causes reduction of edema and accelerates metabolic processes in the tissues (Chauhan et al., 2016; Lindley et al., 2016). They quickly cause osmotic balance, which prevents dehydration of the wound tissues; the ointment base efficiently absorbs the wound content and the active pharmaceutical ingredients penetrate to deep layers of the wound. Osmotic effect lasts for 18 hours, which allows the bandage to be changed only once a day.

In previous studies by Davtian (2009) the osmotic activity of soft pharmaceutical formulations was conditionally divided into low (to 83\%), average (to 19\%) and clearly manifested osmotic activity (from $240 \%$ ). Therefore, considering this and the results of our studies, the ointment we have developed is capable of clear osmotic activity. In our case, this was conditioned by the pharmaceutical form and adjuvants.

Reasoning behind the selection of emulsifiers for stabilizing the hydrophilic base. Many studies (Mastropietro et al., 2013; Merkle, 2015) have proved that emulsifiers have a key role in pharmacodynamics of emulsion preparations. Surfactants in soft pharmaceutical forms always positively affect the processes of absorption of active pharmaceutical ingredients, and greatly contribute to manifestation of their activity. A number of studies (Kukhtenko et al., 2012; Rudenko, 2012) have proved that obtaining a stable emulsion with satisfactory consumer indicators and viscous-flexible characteristics is possible at concentration of the oil phase of $20 \%$.

The authors (Mastropietro et al., 2013; Abrantes et al., 2015) have mentioned that the stability and the best viscous-flexible and thixotropic properties of emulsions provide usage of the mixtures of surfactants of the first and the second generations in certain proportions, leaving their total concentration constant (8\%). Due to this fact, when selecting emulsifiers for stabilizing the emulsion, we analyzed the dependency of rheological indicators of emulsions on the nature, ratio and the number of emulsifiers of the first and the second generations. For accuracy of the analysis, we changed the nature of the surfactants at their constant total concentration of $8 \%$, and the content of the other components (liquid paraffin - 20\%, PEO-1500 - 1\%, PEO-400 - 4\%, glycerine -
$5 \%$, purified water - to $100 \%$ ). The results of our research have shown that the structural viscosity of the system depends on the concentration of emulsifiers. It should mentioned that the highest viscosity among the combinations of emulsifiers was observed in the model compositions 4 and 6 with concentration of cetostearyl alcohol and monoglyceryl stearate in the ratios $70 \%$ / 1\%, 5\% / 3\% respectively. Increase or decrease in the concentrations of emulsifier combinations causes significant increase or decrease in the structural viscosity of the systems. The character of the rheograms indicates that the increase of the shear speed involves occurrence of a directly proportional dependency of shear stress on the deformation speed. This also indicates the relation of the ointment bases to viscous-flexible bodies with a certain structure.

Proving the selection of hydrophilic non-aqueous solvents for the ointment composition. A number of authors (Maitz, 2015; Kiamahalleh et al., 2017) mention glycerine as one of the most common hydrophilic non-aqueous solvents in production of pharmaceutical formulations of local application. It is able to affect the main technological and biopharmaceutical characteristics of a preparation. Also, glycerine is recognized as a classic moisturizing and softening pharmaceutical agent and is capable of being a penetrant and a solubilizer. When it is applied to the skin, this compound absorbs water from the subepidermal layers, forming a hydrogen bond with it. Therefore, it prevents the loss of moisture by keeping the water in the derma. Another significant peculiarity of glycerine is that its molecules structure the extracellular fluid and protect the cells against damage from excessively high osmotic impact. Moreover, glycerine increases transepidermal penetration of water and other substances (Rudenko et al., 2013; Swarbrick, 2013). Like the other hydrophilic non-aqueous solvents, glycerine influences the frost-resistance and osmotic properties of the base, and also the absorption of active pharmaceutical ingredients (Haag and Kratz, 2006).

Introducing glycerine to the compound of the developed pharmaceutical form was mostly conditioned by the necessity to heighten the moisturizing and softening properties of the base. These indicators were the main criteria. Also, the inclusion of glycerine in the proposed composition positively affects the following characteristics of the base: viscosity and other rheological indicators, speed of absorption of active pharmaceutical ingredients; adhesion on application; osmotic properties. It should be mentioned that when using glycerine included in the ointment base, the phase of active osmosis is followed by the phase of "reverse osmosis". This solvent is capable of a penetrating effect, which allows its molecules enter the aqueous environment through the membrane. Due to these properties, glycerine allows the creation of ointment bases with a prolonged but a mild dehydrating effect (Swarbrick, 2013; Sheskey et al., 2017). According to the authors (Rudenko, 2013; Islam et al., 2014), it is recommended that cosmetic and pharmaceutical preparations for external application should include glycerine as an active moisturizing component in the amount of up to $15 \%$. At higher content, surplus glycerine forms a non-drying membrane on the skin. Generally, for providing moisturizing and alleviating properties, glycerine is used in concentrations of $5 \%$ or $10 \%$ (Cardinal et al., 2009).

Determining the optimum concentration of active pharmaceutical ingredients in the compound of the developed ointment. The data from the literature on the treatment of purulent inflectional skin processes caused by a wide range of bacteria and associations with pathogenic fungi have shown the advantages of using broad-spectrum antibiotics in combinations with non-steroidal anti-inflammatory preparations (Biryukova et al., 2009; Barajas-Nava et al., 2013). Considering the etiopathogenesis of development of purulent-inflammatory processes of the skin, the antibacterial component the authors used was ofloxacin (such choice was based on the practical absence of resistance to it, both natural and obtained, among bacterial associations), and a nonsteroidal anti-inflammatory preparation - nimesulide, which is able to inhibit proteolytic enzymes, stabilizes protein structures of cell membranes (Dohmen, 2008; Kopenkin and Talitsky, 2013). Research on using in vitro and in vivo ofloxacin-nimesulide combinations of active pharmaceutical ingredients in the compound of the studied ointment was conducted by the authors for the first time. Experimental studies determined that under the impact of Oflocain ointment the speed of wound 
healing was insignificantly higher that the wound-healing speed among the animals treated with Nimulid gel. It should be mentioned that all tested compositions showed higher anti-alternative activity compared to Oflocain and Nimulid, which showed the speed of wound-healing of $76 \%$ and $92 \%$ respectively on the 15th day of treatment, whereas the tested combinations achieved full healing on the 11th day of treatment. Thus, we found that combining active substances of antibacterial and anti-inflammatory effect in one pharmaceutical form reduces the concentration of antibacterial preparation at nearly the same indicators of anti-alternative activity compared to the comparative preparation.

The selection of an anesthetic pharmaceutical substance in the compound of the ointment. Contemporary medicine possesses a variety of pharmaceutical formulations for local anesthesia, which are used in different pharmaceutical forms (Atiyeh et al., 2009). The effect of local anesthetics is classified according to its depth, efficiency, duration and reverse anesthetic effect, for only a few of them are widely used in practical medicine. Data from the literature indicates that the anesthetic effect and toxicity of local anesthetics is usually compared to Novocaine, the forefather of this group of preparations; its indicators are considered to equal one (Rüttermann et al., 2013; Sheskey et al., 2017). The conducted experiment showed that with lidocaine concentrations from $1 \%$ to $4 \%$, the depth and duration of anesthesia increases and the time of beginning significantly decreases. Further increase in the content of lidocaine (4\% to $10 \%$ ) affects the local anesthetic effect insignificantly.

Determining the impact of the method of introducing the active pharmaceutical ingredients to the ointment compound and their antibacterial effect. A significant feature of modern applicatory pharmaceutical forms is regulation of the speed of provision and concentration of the active pharmaceutical ingredients in the blood circulation system. None of the traditionally used transdermal pharmaceutical forms possesses such property. For this purpose, different methods were used (Davtian, 2009; Maitz, 2015). The regulation of release of active pharmaceutical ingredients from the ointment is suggested to be done either through using different ratios of the bases, or through introduction of dimethyl sulfoxide (Abrantes et al., 2016). Considering the physicalchemical properties of active pharmaceutical ingredients for determining the optimum method of their introduction to the compound of the base, ofloxacin and nimesulide were introduced in a form of a solution in dimethyl sulfoxide, suspension with PEO-400, suspension with glycerine and suspension with liquid paraffin (Biryukova et al., 2009). Lidocaine is easily soluble in water and hydrophilic non-aqueous solutions; therefore it was introduced to the ointment base in the form of solution in water, solution in dimethyl sulfoxide and solution in PEO400 (Debjit et al., 2012; Chauhan et al., 2016).

The analysis of antibacterial activity of the samples in relation to the method of introducing active pharmaceutical ingredients showed that when ofloxacin and nimesulide were introduced in the form of suspension with glycerine, with PEO-400, and with liquid paraffin, the zone of strain growth inhibition around the wounds did not exceed those present when ofloxacin and nimesulide were introduced in the form of solution in dimethyl sulfoxide and equalled $24.3 \pm 0.2,24.2 \pm 0.5,23.4 \pm 0.6$, $24.0 \pm 0.6,23.3 \pm 0.5 \mathrm{~mm}$ for $E$. coli, $K$. pneumoniae, C. albicans, S. aureus, $B$. subtilis and $P$. aeruginosa respectively.

Proving the selection of temperature regime for the technology of preparing the ointment. The research we conducted showed that the temperature affects the antibacterial activity of ointment and this proves the statements of particular authors (Davtian, 2009; Swarbrick, 2013). The lowest antibacterial activity in the samples is related to the decomposition of the active pharmaceutical ingredients included in the ointment. The National Pharmacopoeia of Ukraine (Hryzodub et al., 2015) requires all ointments to possess constant rheological characteristics, for the latter reflect both medical and consumer properties of pharmaceutical formulations. This requirement is related to obtaining a pharmaceutical composition with optimum structural-mechanical (rheological) properties in the course of its development, reproducing and maintaining its capacities in the process of technical processing of its components and production of drugs, and also to maintenance and use of pharmaceutical formulations by consumers. The authors (Gullapalli,
2010; Sheskey et al., 2017) mention that this aspect should consider both the interaction of the components and external factors (temperature, method and duration of processing, conditions and time of maintenance, transportation, etc.), which affect the quality of the product. The research we conducted fulfills the requirement of the National Pharmacopoeia of Ukraine.

Analysis of the results (Fig. 5 and 6) showed that all curves were characterized by gradual increase in the deformation speed. Further, the rheograms turn into a straight line; this indicates full decomposition of the structure. As the results suggest, the studied ointment is a nonNewtonian fluid. Its fluidity begins after a certain mechanical pressure is reached, i.e. after increasing kinetic energy of the particles of the structural framework, which leads to rupture of connections among its elements. After increase in the shear speed, the shear curves gradually increase, and further gradually turn into straight lines; this indicates gradual full decomposition of the structure. The developed curves also indicate that their flow does not start rapidly, but after certain applied pressure required for a rupture in the structural elements. Over a period of decreasing stress, the viscosity of the samples gradually recovers. This proves the flexible-viscous and thixotropic properties of the samples. Over the period of shear stress reduction, the previous structure recovers later. On downward and upward rheograms, the curves form "hysteresis loops"; this proves the thixotropy of the studied systems.

Analysis of the structural-mechanical properties of the developed ointment. From a practical perspective, a number of authors (Islam et al., 2014; Isaac et al. 2015) have mentioned that study of such properties of ointment bases as ease of application, extrusion from the tubes is of great importance; these properties are defined by the extent of thixotropy of the studied systems. The obtained results led to the conclusion that the consistency of the ointment base and the ointment itself is satisfactory (Fig. 7). Determining the structural-mechanical properties of the ointment indicate that it is a structured system, possesses thixotropic properties, which provide good consumer (ease and convenience in application) and technological (packaging) properties.

\section{Conclusions}

To sum up the accumulated experience in treating wounds and modern knowledge on the wound process and biology of the wound, the conclusion can be drawn that successful prevention and fast treatment of the mentioned pathological condition is possible using a complex method and taking general measures. A significant increase in the effectiveness of treating wound infections could be provided by using the combined ointment developed by the authors. Its composition was scientifically proven in relation to the pathogenesis of the wound process, taking into account its phases and the character of the microflora.

According to the results of microbiological studies (in vitro), we selected an optimum concentration of an antibacterial substance - ofloxacin (0.05 g), for the ointment compound and developed an optimum method of introducing active pharmaceutical ingredients to the ointment base (solution in dimethyl sulfoxide).

Pre-clinical studies (in vivo) proved that combining active substances of antibacterial and anti-inflammatory effect in one pharmaceutical form reduces the concentration of the antibacterial preparation at nearly the same indicators of anti-alternative activity compared to the comparative preparation.

Physical-chemical studies proved PEO-1500 and PEO-400 (1 : 4) to be the optimum base for the ointment; its osmotic properties eliminate purulent discharge. By forming complexes with antibacterial compounds, PEO-400 provides uniform and prolonged absorption of the exudates. Structural-mechanical research proved the concentration of the mixtures of emulsifiers of the first and the second generations - cetylstearyl alcohol and monoglyceryl stearate in the ratios of 3\% and 5\% respectively at $20 \%$ concentration of oil phase.

The conducted rheological research on the developed preparation proved that it corresponds to the requirements we set. It was proved that the developed preparation's consistency is satisfactory, for the shear stress curves fully fit the range of rheological optimum for hydrophilic ointments. The areas of the rheograms of the ointment's effect are situa- 
ted in the zone of rheological optimum, which proves its satisfactory application ability.

It was proved that the temperature factor in the technological process affects the antibacterial properties of the ointment. The obtained results of our biological and biopharmaceutical research on developing a complex ointment for wound treatment could be a basis for clinical studies and introduction to serial industrial production.

\section{References}

Abrantes, C. G., Duarte, D., \& Reis, C. P. (2016). An overview of pharmaceutical excipients: Safe or not safe. Journal Pharmaceutical Science, 105(7), 20192026.

Alves, M. P., Scarrone, A. L., Santos, M., Pohlmann, A. R., \& Guterres, S. S. (2007) Human skin penetration and distribution of nimesulide from hydrophilic gels containing nanocarriers. Pharmaceutical Nanotechnology, 341(1-2), 215-220.

Atiyeh, B. S., Dibo, S. A., \& Hayek, S. N. (2009). Wound cleansing, topical antiseptics and wound healing. International Wound Journal, 6(6), 420-430.

Barajas-Nava, L. A., López-Alcalde, J., Solà, I., Roqué i Figuls, M., \& Bonfill Cosp, X. (2013). Antibiotic prophylaxis for preventing burn wound infection. Cochrane Database of Systematic Reviews, 6 .

Biryukova, S. V., Tarasenko, V. A., Kolokova, A. B., \& Davtyan, L. L. (2009). Vyvchennya antymikrobnoyi aktyvnosti kremu ta helyu na osnovi tseftryaksonu ta nimesulidu [Study of the antimicrobial activity of the cream and gel on the basis of ceftriaxone and nimesulide]. Farmatsevtychnyy Chasopys, 9(1), 52-56 (in Ukrainian).

Cardinal, M. M., Eisenbud, D. E., \& Armstrong, D. G. (2009). Serial surgical debridement: A retrospective study on clinical outcomes in chronic lower extremity wounds. Wound Repair and Regeneration, 17(3), 306-311.

Chan, B. A., Xuan, S., Li, A., Simpson, J. M., Sternhagen, G. L., Yu, T., Darvish, O. A., Naisheng, J., \& Zhang, D. (2017). Polypeptid polymers: Synthesis, characterization, and properties. Biopolymers, e23070.

Chauhan, N. P. S., Pathak, A. K., \& Bhanat, K. (2016). Encyclopedia of biomedical polymers and polymeric biomaterials. Taylor \& Francis, New York.

Davtian, L. L. (2009). Tekhnolohichnyy sposib vvedennya diyuchykh rechovyn do osnovy preparatu [Technological method of introduction of active substances to the basis of the preparation]. Military Medicine of Ukraine, 12(4), 61-63 (in Ukrainian).

Debjit, B., Harish, G., Pragati, K. S., Duraivel, K. P., \& Sampath, K. (2012). Recept advances in novel topical drug delivery system. The Pharma Innovation, $1(9), 12-31$.

Dohmen, P. M. (2008). Antibiotic resistance in common pathogens reinforces the need to minimize surgical site infections. Joumal of Hospital Infection, 70(2), 15-20.

Farooq, U., Rishabh, M., Bansal, V., \& Pragati, K. S. (2014). Characterization of some polymers as pharmaceutical excipient. Advances in Biological Research, 8(3), 123-126.

Gullapalli, R. P. (2010). Soft gelatin capsules (softgels). Journal Pharmaceutical Science, 99(10), 4107-4148.

Haag, R., \& Kratz, F. (2006). Polymer therapeutics: Concepts and applications. Angewandte Chemie International Edition in English, 45(8), 1198-1215.

Healy, B. M., \& Freedman, A. M. (2010). ABC of wound healing infections. British Medical Journal, 332, 838-841.

Hotz, B. V., Visekruna, A. A., Buhr, H. J., \& Hotz, H. G. (2010). Beyond epithelial to mesenchymal transition: A novel role for the transcription factor snail in inflammation and wound healing. World Journal of Gastrointestinal Surgery, 14(2), 388-397.

Hryzodub, O. I. (ed.), (2015). Derzhavna farmakopeya Ukrayiny [State pharmacopoeia of Ukraine]. Ukrayins'kiy Naukoviy Farmakopeyniy Tsentr Yakosti Likars'kykh Zasobiv, Kharkiv (in Ukrainian).
Isaac, V. L. B., Chiari-Andreo, B. G., Marto, J. M., Moraes, J. D. D., Leone, B. A., Correa, M. A., \& Ribeiro, H. M. (2015). Rheology as a tool to predict the release of alfa-lipoic acid from emulsions used for the prevention of skin aging. BioMed Research International, 2015, 1-8.

Islam, M. T., Rodríguez-Hornedo, N. P., \& Ciotti, S. E. (2014). Rheological characterization of topical carbomer gels neutralized to different $\mathrm{pH}$. Journal Pharmaceutical Research, 7(21), 1192-1199.

Janis, J. E., \& Harrison, B. (2016). Wound healing: part I. Basic science. Plastic and Reconstructuctive Surgery, 138(3), 9-17.

Kadajji, V. G., \& Betageri, G. V. (2011). Water soluble polymers for pharmaceutical applications. Polymers, 3(4), 1972-2009.

Kiamahalleh, M. V., Mellati, A., Madani, S. A., Pendleton, P., Zhang, H., \& Hadi Madani, S. H. (2017). Smart carriers for controlled drug delivery: Thermosensitive polymers embedded in ordered mesoporous carbon. Journal of Pharmaceutical Science, 106(6), 1545-1562.

Kopenkin, S. S., \& Talitsky, K. A. (2013). Mestnoye primeneniye nesteroidnykh protivovospalitel'nykh sredstv v travmatologii i ortopedii [Local use of nonsteroidal anti-inflammatory drugs in traumatology and orthopedics]. Visnyk Ortopedii, Travmatologii i Protezuvannya, 1, 77-80 (in Ukrainian).

Lindley, L. E., Stojadinovic, O., Pastar, I., \& Tomic-Canic, M. (2016). Biology and biomarkers for wound healing. Plastic and Reconstructive Surgery, 138(3), 18-28.

Maisch, T. (2007). Anti-microbial photodynamic therapy: Useful in the future. Lasers in Medical Science, 22(2), 83-91.

Maitz, M. F. (2015). Applications of synthetic polymers in clinical medicine Biosurface and Biotribology, 1(3), 161-176.

Mastropietro, D. J., Nimroozi, R., \& Omidian, H. (2013). Rheology in pharmaceutical formulations - A perspective. Joumal of Developing Drugs, 2(2), 108.

Merkle, H. P. (2015). Drug delivery's quest for polymers: Where are the frontiers? European Journal Pharmaceutical Biopharmaceutics, 97, 293-303.

Mincer, O. P., Voronenko, Y. V., \& Vlasov, V. V. (2003). Obroblennya klinichnykh i eksperymental'nykh danykh u medytsyni [Treatment of clinical and experimental data in medicine]. Vishha Shkola, Kyiv (in Ukrainian).

Nishio, N. S., \& Suzuki, I. H. (2009). Antibodies to wounded tissue enhance cutaneous wound healing. Immunology, 128(3), 369-380.

Owens, C. D., \& Stoessel, K. P. (2008). Surgical site infections: Epidemiology, microbiology and prevention. Journal of Hospital Infection, 70(2), 3-10.

Puoci, F., Piangiolino, C., Givigliano, F., Parisi, O. I., Cassano, R., Trombino, S., Curcio, M., Iemma, F., Cirillo, G., Spizzirri, U. G., Restuccia, D., Muzzalupo, R., \& Picci, N. (2012). Ciprofloxacin-collagen conjugate in the wound healing treatment. Journal of Functional Biomaterials, 3, 361-371.

Rudenko, V. V., Vlasenko, I. O., \& Vashchuk, V. A. (2013). Vyvchennya osmotychnoyi aktyvnosti kombinatsiy hidrofil'nykh nevodnykh rozchynnykiv dly modelyuvannya preparatu, dlya likuvannya I fazy ranovoho protsesu [Study of osmotic activity of combinations of hydrophilic non-aqueous solvents for modeling a drug for treatment of phase I of the wound process]. Pharmaceutical Journal, 1, 46-49 (in Ukrainian).

Sheskey, P. J., Cook, W. G., \& Cable, C. G. (2017). Handbook of pharmaceutical excipients. APhA/Pharmaceutical Press, London.

Stefanov, O. V. (ed.), (2001). Doklinichni doslidzhennya likars'kih zasobiv [Preclinical studies of medicines]. Avicena, Kyiv (in Ukrainian).

Trostrup, H., Bjarnsholt, T., Kirketerp-Moller, K., Hoiby, N., \& Moser, C. (2013). What is new in the understanding of non-healing wounds epidemiology, pathophysiology and therapies. Ulcers, 2013, ID 625934.

Victorov, O. P., \& Kashuba, O. V. (2014). Nimesulid: Otsinymo perspektyvy [Nimesulide: Assessment of the prospects]. Mystetstvo Likuvannya, 5, 20-22 (in Ukrainian).

Vyas, K. S., \& Vasconez, H. C. (2014). Wound healing: Biologics, skin substitutes, biomembranes and scaffolds. Healthcare, 2(3), 356-400. 